\title{
Transfer of Potentially Toxic Metals from Soil to Crops Cultivated on Irrigated Farmlands along River Delimi in Jos, Nigeria
}

\author{
*Sabo, A., ${ }^{1}$ Gani, A. M. ${ }^{2}$, Ibrahim, A. Q. ${ }^{3}$ \\ 1. Department of Environmental Management Technology, AbubakarTafawaBalewa University, P. M. B. 0248, \\ Bauchi. Bauchi State, Nigeria. \\ 2. Department of Biological Sciences, AbubakarTafawaBalewa University P. M. B. 0248, Bauchi. \\ Bauchi State, Nigeria. \\ 3. Department of Chemistry, Nigeria Police Academy Wudil, Kano State, Nigeria.
}

*Corresponding Author: Sabo, A., Department of Environmental Management Technology, Abubakar Tafawa Balewa University, P. M. B. 0248, Bauchi. Bauchi State, Nigeria.

\begin{abstract}
The accumulation of heavy metals in agricultural soil is a source of concern because of food safety issues. The present study was aimed at evaluating the Transfer Factors(TFs) of potentially toxic metals (Cd, $\mathrm{Cr}, \mathrm{Cu}, \mathrm{Pb}$ and $\mathrm{Zn}$ ) from soil into the food chain by assessing the levels of these metals in soils and vegetables (Carrot, Cabbage, Lettuce and Spinach) obtained from farmlands along River Delimi in Jos city. The metals content in soils and vegetables were determined using 210 VGP Model, Buck Scientific Atomic Absorption Spectrophotometer $(A A S)$ after extraction with Aqua-regia. The data generated were analyzed using simple descriptive statistics followed by the determination of TFs calculated as the ratio of the concentrations of the metals in crops to the concentrations in soils. The results revealed that both the soil and crop samples collected at the study area contained more metals than those at the control site. Additionally, the metals generally had highest TFs values at the study area compared to the control site. The least TFs values for these metals in the crops at the control site could be attributed to the lower mean total metals content in the soils. This further suggests that plant absorption of these metals was mainly controlled by the content that is available in the soil. It is recommended that farmers should cultivate plant species (legumes, cereals, potatoes etc.) with low metal uptake and avoid the cultivation of crops such as carrots, spinach, lettuce that are known to accumulate high amount of metals. The metal transfer into food chain could also be reduced through cultivation of industrial crops such as Jatrophaand castor plants known for their high oil content. Furthermore Farm Yard Manure should be applied to the soil as it reduces the bioavailability of the heavy metals to the crops
\end{abstract}

Keywords: Soil; Vegetable; Consumption; Metal; Transfer factor; Health risk

\section{INTRODUCTION}

Soils are known to have many important functions. However, the most appreciated is their ability to support the growth of plants. The soil's natural cycles ensure the provision of adequate physical, chemical and biological medium for crop production. Farmers therefore have acquired the skills in managing soils so that certain essential elements (if need be) can be added to the natural cycles to enhance the soil quality and increase crop production. Consequently, soils have been cultivatedfor centuries to produce increasing amounts of food to keep pace with the needs of the ever increasing human population. The ability of the soil to serve as a growth medium for crop production is however hampered by the accumulation of excess amount of pollutants such as heavy metals.

Sources of heavy metals in soils include natural occurrence derived from parent materials and human activities (anthropogenic sources). Anthropogenic inputs are associated with industrial and agricultural activities such as atmospheric deposition, waste disposal, waste incineration, urban 
effluent, vehicle exhausts, fertilizer application and long-term application of sewage sludge on agricultural land $[1,2]$.

Plants as essential components of natural agro-ecosystems represent the first compartment of the terrestrial food chain [3].According to [4], excessive accumulation metals in agricultural soils results in soil contamination and has consequences for food quality and safety. The consumption of certain food crops cultivated on soils that contained excess amount of toxic metals could be a threat to human health. This is essentially due to the ability of such crops to accumulate high amount of these metals in their edible parts.

Soil-to-plant transfer is the major pathway of human exposure to metal pollutants insoil [5]. TF is the ratio of the concentration of an element in an organism to the concentration in the source medium [6]. According to this theory, the concentration of some elements in plants has linear relationships with some concentrations in the soil. TFs of heavy metals from soil to vegetation can only be established when a linear relationship is observed between the soil and plant concentrations.Thus values of TF are used for many assessment models to predict the concentrations of elements in plants taken from soil [7]. Moreover, it is a convenient way of quantifying the relative differences in bioavailability of metals to plants [8]. Additionally, TF of heavy metals from soil to crops is one simple way of predicting human exposure to metals through the food chain [9].

The present study was aimed at evaluating the TFs of potentially toxic metals from soil into the food chain by assessing the levels of these metals in soils and vegetable crops obtained from farmlands along River Delimi in Jos city.

\section{Materials ANd Methods}

\section{Study Area}

The study was conducted at designated points along River Delimi in Jos city (Figure 1). Jos is a city in the north-central Nigeria and the capital of Plateau State. It is located on Lat. 9 ${ }^{\mathbf{9}} 52$ '59'' $\mathrm{N}$ and Long. $8^{0} 54$ '26''E. It has an altitude of about 1,238 metres or 4,062 feet high above sea level. The river covers a distance of about $15 \mathrm{~km}$ as it passes through the city. It mainly originates from Delimi village located few kilometers to the southern outskirts of Jos city. The Delimi River serves as the major source of water for urban agriculture in Jos. 


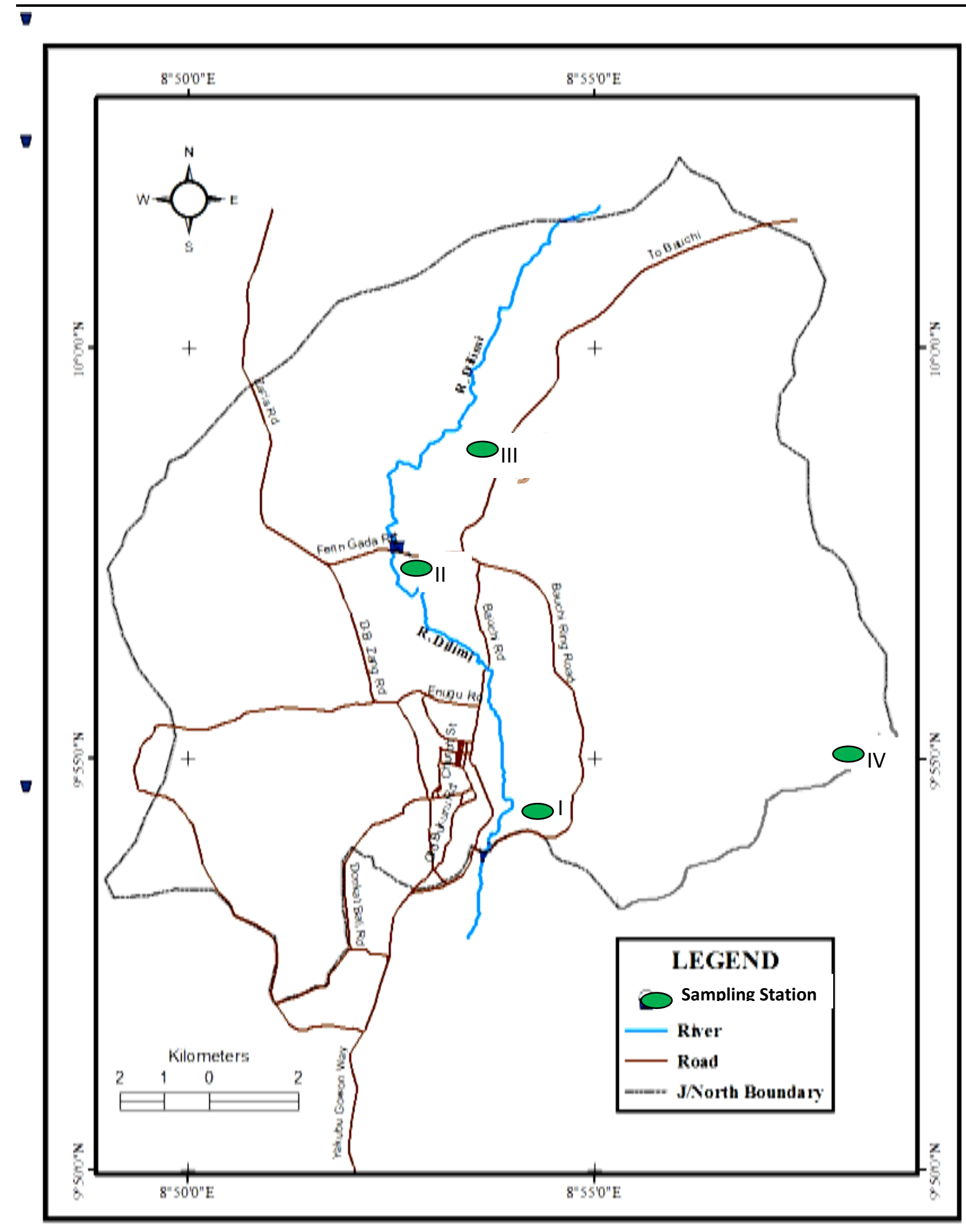

Figure 1.Map of Jos metropolis showing the sampling stations

\section{Experimental Design and Sampling Strategy}

The experiments to determine the heavy metal contents in soil and vegetable crops were conducted along River Delimi (study area) and Lamingo dam (control site) in Jos city. Four stations were identified and in each station a Complete Randomized Design (CRD) was used for the investigation.

Samples of overbank soil and vegetable crops (Carrot, cabbage, lettuce and spinach) were collected from the four sampling stations along the river (study site) and Lamingo Dam (control site) as follows: 
- $\quad$ Station I = Gangare (Lat. $9^{0} 53^{\prime}$ 22'’N, Long. $8^{0}$ 52'57'’E )

- Station II = FarinGada (Lat. $9^{0} 57^{\prime} 36^{\prime}$ 'N, Long. $8^{0} 52^{\prime} 27^{\prime}$ 'E $)$

- $\quad$ Station III = University of Jos main campus (Lat. $9^{0} 58^{\prime} 52^{\prime}{ }^{\prime}$ N, Long. $8^{0} 52^{\prime} 54^{\prime \prime} \mathrm{E}$ )

- Station IV = Lamingo Dam (Lat. $9^{0} 53^{\prime} 07^{\prime}$ ' Long. $8^{0}$ 54'55') served as control station

The choice of study stations was purposive based on the availability of the crops in order to ensure uniformity and consistency. Vegetables identified as samples at designated points were purchased directly from farmers [10]. Soil samples were obtained with soil auger at a depth not exceeding $15 \mathrm{~cm}$ at each point where the vegetables were collected [11]. The sampling procedures were performed in rainy and dry seasons.

\section{Soil and Plant Analysis}

Soil and vegetable samples were collected in a polythene bags and kept on ice. The samples were subsequently transported to the laboratory and kept at $4^{0} \mathrm{C}[12]$. The heavy metals content in the soil and vegetable samples were determined using 210 VGP Model of Buck Scientific Atomic Absorption Spectrophotometer (AAS) after extraction with Aqua-regia.

\section{Statistical Analysis}

The data generated in the course of this investigation were analysed using simple descriptive statistics. This was followed by the determination of Transfer Factor (TF) calculated for the heavy metals according to the formula given by $[13,14,15]$

$\mathrm{TF}=C p(\mathrm{mg} \mathrm{kg}-1$ dry wt $) / C t s(\mathrm{mg}$ kg-1 dry wt $)$,

Where, $C$ is the plant metal content and Ctsis the total metal content in the soil.

\section{RESULTS AND DISCUSSION}

\section{Metals TF in Carrot}

The TF of metals in carrot determined at different sampling stations in the study and control sites are as presented in Figure 1.

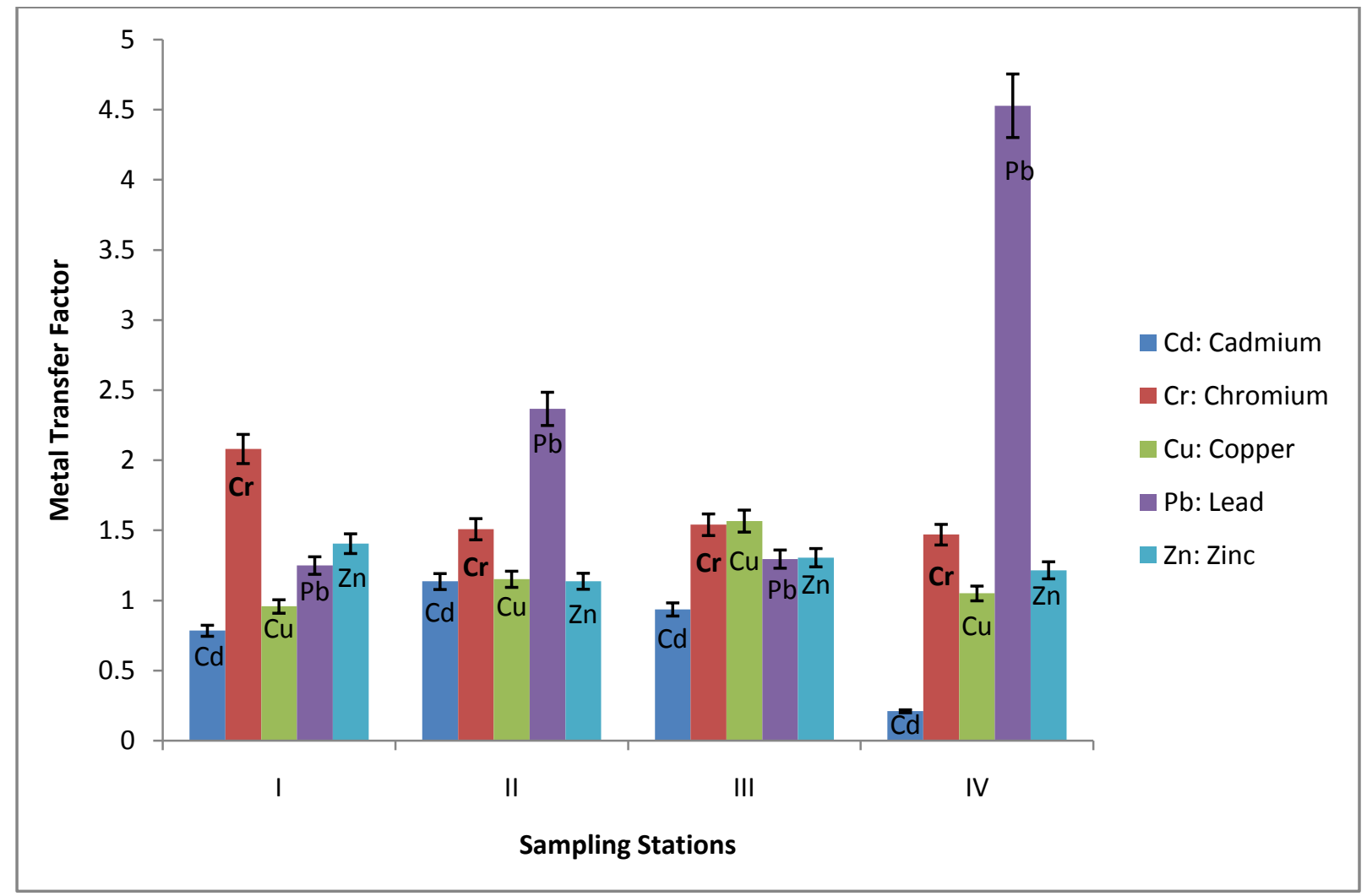

Figure 1.Mean Transfer Factor of metals in carrot obtained from four sampling stations along River Delimi and Lamingo Dam in Jos metropolis 
The maximum $\mathrm{TF}$ of $\mathrm{Cd}$ (1.136) was recorded in carrot samples obtained at station II while the least was in those samples collected at station IV (0.211). The TFs of Cd in the same crop at stations I and III were 0.785 and 0.937 respectively. The accumulation of $\mathrm{Cr}$ in carrot was higher at station I (2.081) followed by stations III (1.541) and II (1.509) and the least in samples recovered from station IV (1.470). There was low accumulation of $\mathrm{Cu}$ in carrot samples at station I (0.958) while the maximum was at station III (1.567). Stations II and IV had closely similar TFs of 1.152 and 1.051 respectively. At station II, there was high accumulation of $\mathrm{Pb}$ in carrot up to 2.367 . $\mathrm{Pb}$ TF values in carrot at the other sampling stations were; station I (1.250), station III (1.296) and station IV (0.288). Zn bioaccumulation values in carrot at stations I, II, III and IV were 1.406, 1.138, 1.306 and 1.216 respectively.

It was observed that with the exception of $\mathrm{Cu}$, all the metals had their least TFs at the control compared to the study site. This may be due to the fact that at the control site, greater percentages of these metals as earlier pointed out by [16] were in residual fractions which prevent their absorption by the crop. The least TFs for these metals in the crop at the control site may also be due to the lower mean total content of the metals in the soils. This suggests that plant absorption of these metals was controlled by the content that is available in the soil.

\section{Metals TF in Cabbage}

The heavy metals TF values from soil to cabbage varied from one sampling station to another as shown in Figure 2.

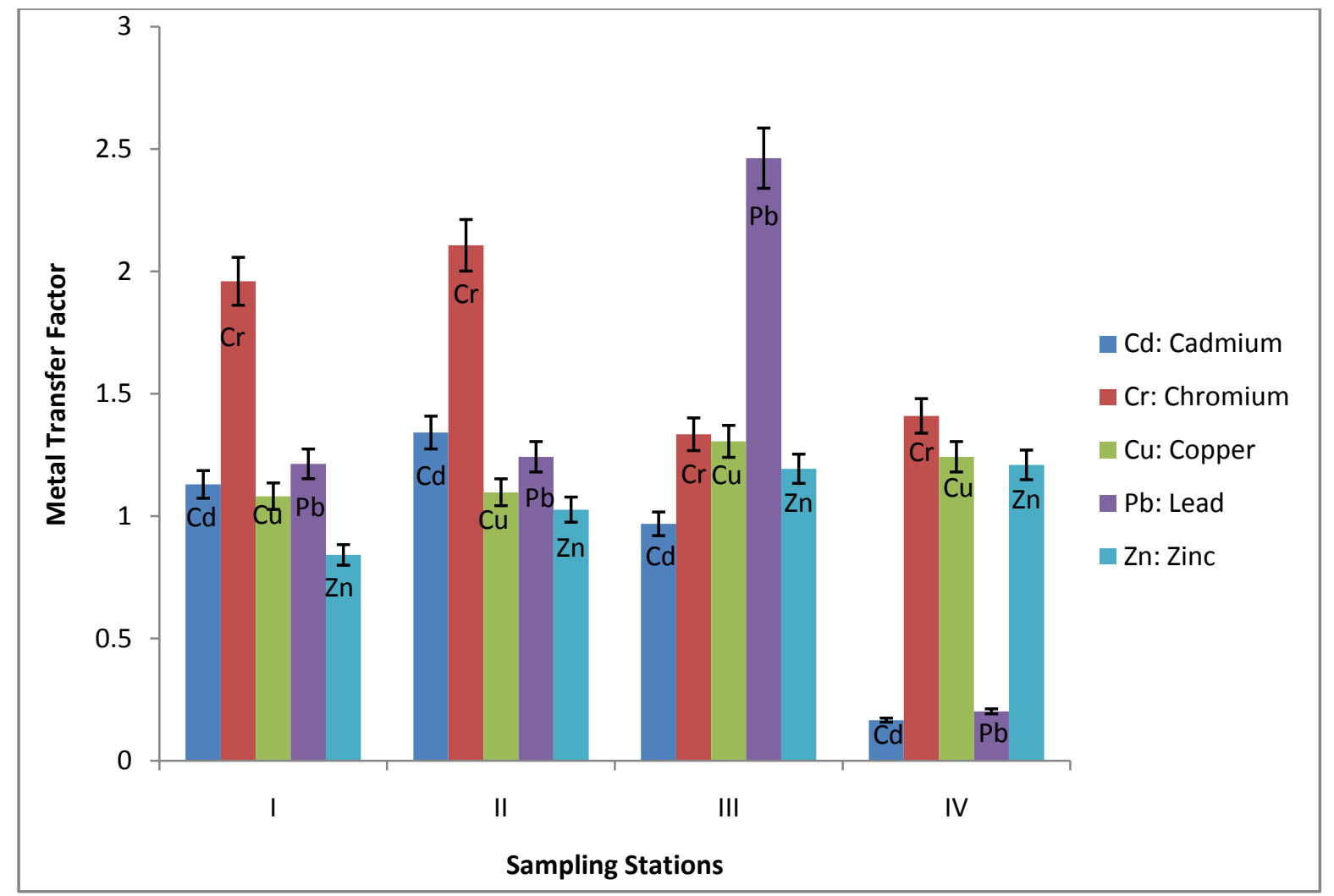

Figure 2.Mean Transfer Factor of metals in cabbage obtained from four sampling stations along River Delimi and Lamingo Dam in Jos metropolis

A trend similar to that found in carrot was observed in cabbage crop in the bioaccumulation of $\mathrm{Cd}$ with the highest value recovered in samples obtained from station II (1.341) and the least at station IV (0.166). The amount of Cd recorded in the crop samples at stations I and III were 1.129 and 0.968 respectively. The maximum $\mathrm{TF}$ for $\mathrm{Cr}$ (2.106) in cabbage was observed at station II, followed by 1.959 and 1.409 at stations I and IV respectively and the lowest value (1.334) at station III. The uptake of $\mathrm{Cu}$ by the crop was relatively higher in samples obtained from stations III (1.305) and IV 
(1.242) compared to the values at station (1.081) and station II (1.097). There was a very low accumulation of $\mathrm{Pb}(0.1861)$ by cabbage at station IV (control site) compared to 1.213, 1.242 and 2.462 recorded in the crop respectively at stations I, II and III. In contrast to the case of $\mathrm{Pb}, \mathrm{Zn}$ accumulation (0.841) was low in cabbage obtained from station I of the study site while the maximum accumulation (1.209) was observed in samples at station IV of the control site. The metal bioaccumulation values at stations I and II were 1.026 and 1.93 respectively.

In cabbage, the maximum TF values of all the metals (except $\mathrm{Zn}$ ) were at the study site. The least TF values for $\mathrm{Cd}$ and $\mathrm{Pb}$ at station IV may be due to their lower mean values in the soil. Similar higher TF values in plants due to higher mean metal content of their associated soils were obtained by [17]. The cabbage has accumulated less $\mathrm{Cu}$ at station I probably due to higher OM content of the soil. OM in soil prevents the release of metals due to the formation of Metal-OM complex. This was in agreement with the findings of [18] who opined that OM content and other soluble compounds in soil influences the transfer of metals from soil to plants. As the amount of $\mathrm{OM}$ increases, there is atendency for more metals to be absorbed on the soilcomplex and hence reduce their mobility [19].The least amount of $\mathrm{Cr}$ recorded at station III may be due to higher association of the metal with residual non- extractable fractions which makes the metal less available. The crop had accumulated a lot of $\mathrm{Zn}$ at the control site and less amount at station I probably due to the nature of the partitioning of the metal in soil. It was earlier reported [16] that at the control site, only $11.4 \%$ of $\mathrm{Zn}$ was found associated with the residual fraction and a greater portion of the metal was partitioned mainly to other non-residual fractions. This suggests that the metal was highly mobile and can easily be transferred from soil to the crop. It was also earlier reportedthat station I had the highest $\mathrm{Zn}$ percentage residual fraction (48.8\%) [16] This probably prevented the release of the metal since it associates more with the crystalline non-extractable fraction.

\section{Metals TF in Lettuce}

The heavy metals TF values from soil to Lettuce at various sampling points in the study and control sites are as presented in Figure 3. The least Cd TF of 0.181 was recorded in lettuce samples collected at station IV of the control site compared to what were realized in the crop at station I (1.237), II (1.871) and III (1.121) of the actual study site. Cr bioaccumulation in lettuce at stations I, II, III and IV were $2.479,1.042,3.784$ and 1.556 respectively. $\mathrm{Cu}$ bioaccumulation in the crop at stations I (0.989), II (1.189), III(0.823) and IV(1.011) were relatively similar. Low level of Pb (0.180) was recorded in lettuce samples at station IV, but greater amount at stations I (1.246), II (1.726) and III (1.582). $\mathrm{Zn}$ attained its highest TF value (1.308) in lettuce collected at station III while the lowest value (1.000) was observed in samples obtained from station II.Closely related $\mathrm{Zn}$ TF values 1.262 and 1.287 were recorded in lettuce collected at stations I and IV respectively. 


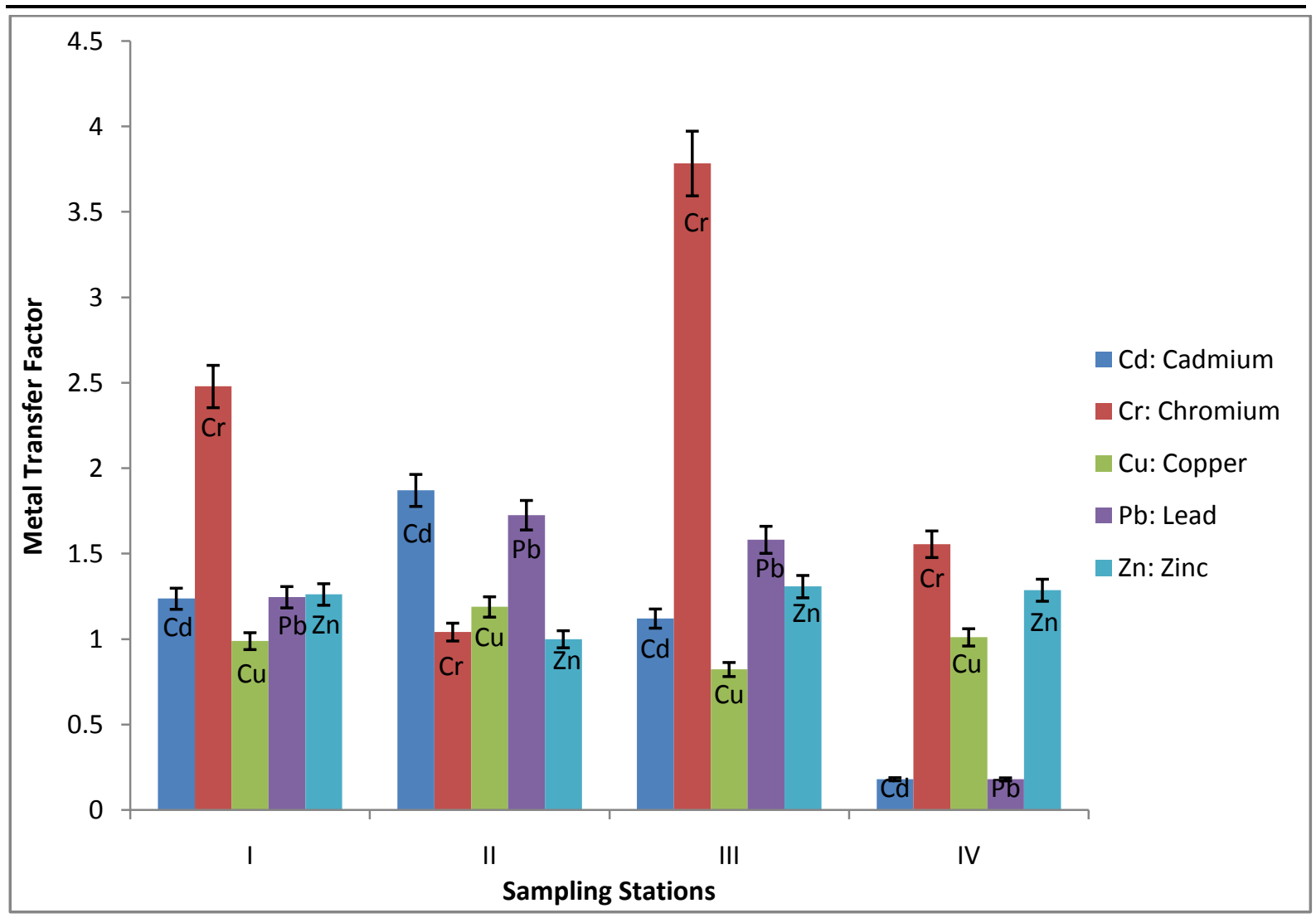

Figure 3.Mean Transfer Factor of metals in lettuce obtained from four sampling stations along River Delimi and Lamingo Dam in Jos metropolis

The least TFs recorded for $\mathrm{Cd}$ and $\mathrm{Pb}$ at stations IV was a reflection of the total mean content of these metals obtained in soil. According to [20], the concentrations of heavy metals in plant tissues as a fraction of total metal content in soil could be a reflections of its bioavailability. It may therefore be concluded that lower $\mathrm{TF}$ values for $\mathrm{Cd}$ and $\mathrm{Pb}$ were obtained because the total metal concentrations at this station were low. The least TFs for Cr at station II may be due to lower mobility of the metal since according to [16] more than 57\% of the total metal content was associated with the residual fraction. Metals bounded to this fraction are not easily released for uptake by plants. The lowest TF value recorded for $\mathrm{Zn}$ at station II may be due to its high association with Organic fraction. This corroborates the findings of [20] who reported that the bioavailability of $\mathrm{Zn}$ depends among other factors on the OM content of the soil. Organic matter is a very important adsorptive source of metals in soils. Organic matter has a high CationExchange Capacity and can adsorb high amount of heavy metals [21]. Interaction with other metals such $\mathrm{Cu}$ found in appreciable quantities in the soil at the same station may also prevent the uptake of $\mathrm{Zn}$ due to antagonism [22].

\section{Metals TF in Spinach}

Figure 4 shows the metals TF values from soil to spinach at different sampling stations of the study and control sites. 


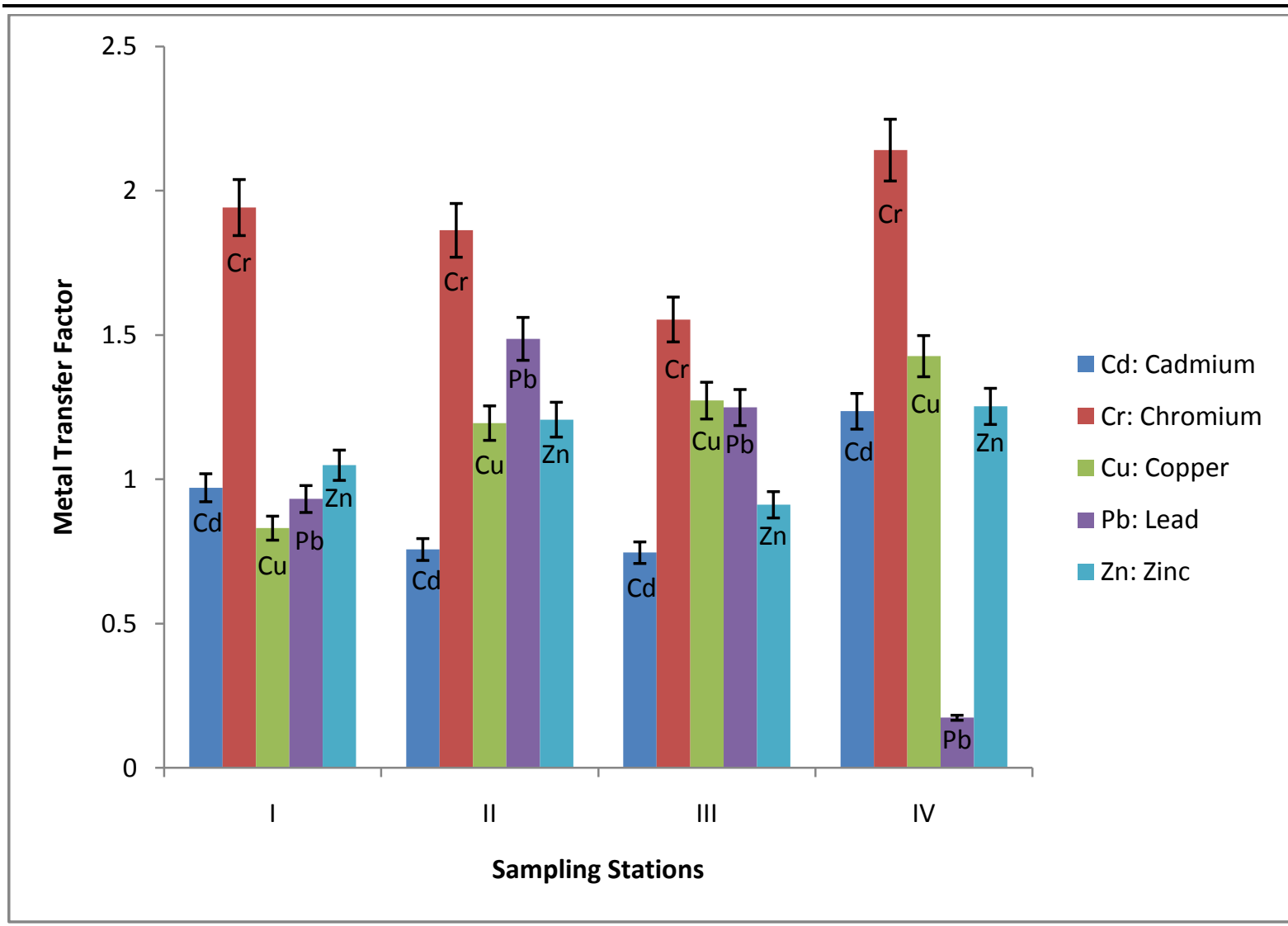

Figure 4.Mean Transfer Factor of metals in spinach obtained from four sampling stations along River Delimi and Lamingo Dam in Jos metropolis.

The highest Cd accumulation in spinach (1.236) was at station IV of the control area followed by 0.971 at station I of the study site. Closely similar but relative lower values were recorded in the crop samples obtained from stations II (0.757) and III (0.746). Similar trend was observed in the accumulation of $\mathrm{Cr}$ where the maximum $\mathrm{TF}$ (2.141) was recorded in spinach samples obtained from the control area (station IV) followed by a value (1.942) recorded in samples from station I. The crop has 1.863 and 1.554 mean Cr TFs recovered from samples at stations II and III respectively. Cu mean TF in spinach was also at its maximum (1.427) in samples collected from station IV. However the next important TF values (1.273 and 1.195) were observed in samples obtained from stations III and II respectively. The least TF value (0.831) was from samples collected at station I. The lowest Cd TF (0.174) was observed in spinach samples collected at station IV (control site) while relatively higher values were realized in the crop at stations I (0.932), II (1.487) and III (1.249) of the study site. The mean $\mathrm{Zn}$ TF values $(1.253,1.207,1.049$ and 0.912$)$ in that order were observed in spinach samples obtained from stations IV, II, I and III respectively.

In spinach, all the metals (except $\mathrm{Pb}$ ) had their maximum $\mathrm{TF}$ values at the control site. This is contrary to the findings of [23] who assessed the risk of metal toxicity of contaminated vegetable from waste water irrigated area of Varanasi, India and reported that the TFs of metals in the control were lower than the values at the study site. Pb transfer factor was less at the control site because of its low concentration in the soil and the fact that little amount of this metal is associated with the easily exchangeable fraction. The high TF values for $\mathrm{Cr}$ and $\mathrm{Zn}$ at the control site despite lower total metal content may not be unconnected with the partitioning of the metals in soil collected under the spinach crop which was mostly dominated by the residual fraction. It is however surprising that the TF values for $\mathrm{Cd}$ and $\mathrm{Cu}$ were at their maximum at the control site despite lower soil total metal content and the relative dominance of the residual fraction in their geochemical partitioning. This scenario may be due to input of these metals from sources other than the soil beneath the spinach. Foliar deposition (e.g. due to pesticides application) on to the aerial part of the plant has been recognized as an important source of metal contamination [24]. 


\section{CONCLUSION ANDRECOMMENDATION}

The least TFs for these metals in the crops at the control site could be attributed to the lower mean total content of the metals in the soils. This suggests that plant absorption of these metals was mainly controlled by the content that is available in the soil.It was also observed that the TF values of the metals for all the crops were mostly greater than 0.5. According to [25], the greater the transfer coefficient value than 0.5 , the greater the chances of vegetables for metal contamination by anthropogenic activities will be and so the need for environmental monitoring of the area. This further indicates the potential health risk associated with the consumption of these vegetables. Farmers should be advised to cultivate plant species (legumes, cereals, potatoes etc.) with low metal uptake and avoid the cultivation of crops such as carrots, spinach, lettuce that are known to accumulate high amount of metals. The metal transfer into food chain could also be reduced through cultivation of industrial crops such as Jatropha and castor plants known for their high oil content. Application of Farm Yard Manure (FYM) that reduces the bioavailability of heavy metals in soils due to its high content of organic matter should be encouraged.

\section{REFERENCES}

[1] Ensink, J. H. J., Simmons, R. W., \& van der Hoek, W.(2004). Wastewater use in Pakistan: The cases of Haroonabad and Faisalabad. In C. A. Scott, N. I. Faruqui, \& L. Raschid-Sally (Eds.) Wastewater use in irrigated agriculture: Confronting the livelihood and environmental realities (pp. 91-100). Ottawa: CAB International in association with the International Water Management Institute and the International Research Development Centre

[2] Emongor, V. (2007). Biosorption of lead from aqueous solutions of varied $\mathrm{pH}$ by kale plants (Brasiccaoleraceaevaracephala). Journal of Agricultural, Food, and Environmental Sciences, 1(2), 1-8.

[3] Smical, A.Hotea, V. Oros, V. Juhasz, J and Pop, E. (2008) Studies on transfer and bioaccumulation of heavy metals from soil into LettuceEnvironmental Engineering and Management Journal 7(5), 609-615

[4] Jolly, Y. N., Islam, A. and Akbar, S. Transfer of metals from soil to vegetables and possible health risk assessment. SpringerPlus 2013 2:385.

[5] Cui, Y. J., Zhu, Y. G., Zhai, R. H., Chen, D. Y., Huang, Y. Z. and Qiu, Y. (2004). Transfer of metals from soil to vegetables in an area near a smelter in Nanning, China. Environment International, 30, 785-791.

[6] Staven, L. H., Rhoads, K., Napier, B. A. and Strenge, D. L. (2003), A Compendium of TransferFactors for Agricultural andAnimal Products. U.S. Department of Energy. Contract DE-AC06-76RL01830. 32 Pp

[7] Chojnacka K, Chojnacka A, Gorecka H, and Gorecki H (2005). Bioavailability of heavy metals from polluted soils to plants. Sci. Total Environ. 337: 175-182.

[8] Alloway, B and .Ayres, D. C (1997) Chemical Principles of Environmental Pollution, Second Edition. CRC Press. 416 pages.

[9] Prabu P .C. (2009). Impact of heavy metal contamination of Akaki River of Ethiopia on soil and metal toxicity on cultivated vegetable crops. EJEAFChe, 8(9): 818-827.

[10] Awofolu, O. R., Mbolekwa, Z., Mtshemla, V. and Fatoki, O. S. (2005) Levels of trace metals in water and sediment from Tyume River and its effects on an irrigated farmland. Water Sourth Africa, 31(1), $234-241$

[11] Obasohan, E. E., Oronsaye, J. A. O. and Eguavoen, O. I. (2007)Determination of post-dredging concentrations of selected trace metals in water, sediment and the freshwater mudfish (Clariasgariepinus) from Ikpoba river in Benin City, Edo State, Nigeria. African Journal of Biotechnology 6 (4), 470-474.

[12] APHA (1992). Standard Method for Examination of Water and Wastewater. $18^{\text {th }}$ ed. American Public Health Authority, Washington D. C.

[13] Adriano, D. C. (2001). Trace elements in terrestrial environments: biogeochemistry, bioavailability and risks of metals. Springer, Washington D. C. pp 867.

[14] Butkus, D. and Baltrnait, E. (2007). Accumulation of heavy metals in tree seedlings from soil amended with sewage sludge. Ekologia, 53(4), 68-76.

[15] Puschenreiter M. and Horak, O. (2000). Influence of different soil parameters on the transfer factor soil to plant of $\mathrm{Cd}, \mathrm{Cu}$ and $\mathrm{Zn}$ for wheat and rye. Die Bodenkultur. 51(1), 3-10.

[16] Sabo, A (2013). Assessment of heavy metals content of River Delimi and their uptake by irrigated vegetables. Unpublished Ph.D thesis, Department of Environmental Management Technology, AbubakarTafawaBalewa University, Bauchi, Nigeria, 319pp 
[17] Ratko, K., Snežana, B., Dragica, O., Ivana, B and Nada, D. (2011) Assessment of heavy metal content in soil and grasslands in national park of the lake plateau of the N.P. "Durmitor" Montenegro. African Journal of Biotechnology 10 (26) 5157-5165.

[18] Hossain, M. Z.; Ullah, S. M.; Ahad, S. A. and Ullah M. B. 2007. Transfer of cadmium from soil to vegetable crops. BangladeshJournal of Scientific and Indistrial Research, 42(3), 327-334

[19] Kashem, M. A., Singh B. R., Imamul, Huq, S.M. and Kawai, S. (20II) Fractionation and mobility of cadmium, lead and zinc in some contaminated and non-contaminated soils of Japan. Journal of Soil Science and Environmental Management. 3(9), 241-249.

[20] Alloway, B. J. 1995. Heavy metals in soils. Second edition. London: Blackie Academic and Professional. London

[21] Alloway , B.J. and Jackson, A. P. (1991). The behaviour of heavy metals in sewage sludge amended soils. The Science of the Total Environment, 100: 151-176

[22] Maiti, S. K. and Jaiswal, S. (2008). Bioaccumulation and translocation of metals in the natural vegetation on fly ash lagoons: a field study from Santaldih thermal power plant, West Bengal, India. Environmental Monitoring and Assessment, 136, 355-370

Citation: A. Sabo et al., "Transfer of Potentially Toxic Metals from Soil to Crops Cultivated on Irrigated Farmlands along River Delimi in Jos, Nigeria ", International Journal of Research in Environmental Science, vol. 4, no. 2, p. 1-10, 2018. http://dx.doi.org/ 10.20431/2454-9444.0402001

Copyright: (C) 2018 A. Sabo et al.. This is an open-access article distributed under the terms of the Creative Commons Attribution License, which permits unrestricted use, distribution, and reproduction in any medium, provided the original author and source are credited. 